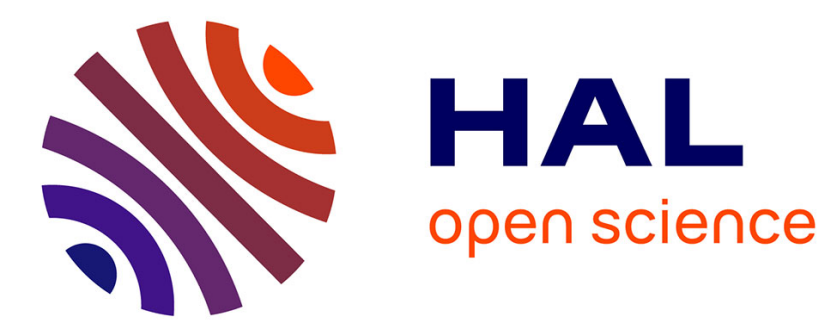

\title{
Variation in developmental time affects mating success and Allee effects
}

Christelle Robinet, Andrew Liebhold, David Gray

\section{To cite this version:}

Christelle Robinet, Andrew Liebhold, David Gray. Variation in developmental time affects mating success and Allee effects. Oikos, 2007, 116 (7), pp.1227-1237. 10.1111/j.2007.0030-1299.15891.x . hal-02657850

\section{HAL Id: hal-02657850 \\ https://hal.inrae.fr/hal-02657850}

Submitted on 30 May 2020

HAL is a multi-disciplinary open access archive for the deposit and dissemination of scientific research documents, whether they are published or not. The documents may come from teaching and research institutions in France or abroad, or from public or private research centers.
L'archive ouverte pluridisciplinaire HAL, est destinée au dépôt et à la diffusion de documents scientifiques de niveau recherche, publiés ou non, émanant des établissements d'enseignement et de recherche français ou étrangers, des laboratoires publics ou privés. 


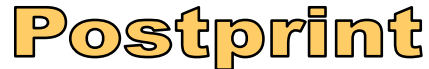

Version définitive du manuscrit publié dans / Final version of the manuscript published in :

Oikos. 2007, 116(7), 1227-1237

Research

15891

Oikos 000: 000-000, 2007

doi:

Copyright (C) Oikos 2007, ISSN 0030-1299

Subject Editor: Tim Benton. Accepted 21 March 2007

Variation in developmental time affects mating success and Allee effects

Christelle Robinet, Andrew Liebhold and David Gray

C. Robinet (robinet@orleans.inra.fr), INRA, UR633 Zoologie Forestière, Avenue de la Pomme de Pin, Ardon, FR-45166 Olivet, France. - CR and A. Liebhold, Northern Research Station, USDA Forest Service, 180 Canfield St., Morgantown, WV 26505, USA. - D. Gray, Natural Resources Canada, Canadian Forest Service, Atlantic Forestry Centre, 1350 Regent St., Fredericton, Canada, NB E3B 5 P7. 


\begin{abstract}
(Abstract)
A fundamental question in biological conservation and invasion biology is why do some populations go extinct? Allee effects, notably those caused by mate location failure, are potentially key factors leading to the extinction of sparse populations. Several previous studies have focused on the inability of males and females to locate each other in space when populations are at low densities but here we investigate the effects of differences in the timing of male and female maturation on mating success. We develop a generalized model to clarify the role of protandry (the appearance of males before female emergence) and variability in adult maturation times. We show that temporal asynchrony can substantially reduce the probability of successful mating. We then apply this generalized model to estimate mating success in invading populations of the gypsy moth in North America in relation to local climate and its associated seasonality. Considerable geographic heterogeneity was observed in simulated mating success and this variability was not correlated with previous evaluations of bioclimatic requirements and habitat suitability. Furthermore, we found that the generalized model of temporal asynchrony provided reliable predictions and that detailed modeling of gypsy moth development was not necessary.
\end{abstract}




\section{(INTRODUCTION)}

One of the key questions that is critical to understanding biological invasions is why many invasions fail. Considerable evidence indicates that only a small fraction of non-indigenous arrivals actually results in an established population (Williamson and Fitter 1996, Ludsin and Wolfe 2001). Several factors may explain the failure of a species to establish; for example, extinction may result from demographic and environmental stochasticities alone (May 1973, Lande 1993, Legendre et al. 1999, Liebhold and Bascompte 2003) as well as from interactions with other species (Murray 1990). Allee effects can also dramatically affect lowdensity populations (Courchamp et al. 1999, Liebhold and Bascompte 2003, Taylor and Hastings 2005). The Allee effect refers to any scenario in which the fitness of individuals is reduced at low conspecific densities (Allee 1949, Stephens and Sutherland 1999, Taylor and Hastings 2005). When a populations' density becomes low, it may consequently fall below some critical threshold at which growth rates decrease and the population declines toward extinction. Understanding the role of Allee effects during invasions is critical, and a greater appreciation of their causes could facilitate the development of strategies to mitigate the impacts of invasions (Liebhold and Bascompte 2003, Taylor and Hastings 2004, Drake and Lodge 2006).

While Allee effects have been observed in populations of many species, the mechanism(s) behind these dynamics are often not clear. Several different mechanisms are known to be capable of generating an Allee effect in low-density populations; these include, (1) a decrease in cooperative interactions resulting in increased susceptibility to predation, reduced care for juveniles and reduced efficiency of host utilization, (2) elevated inbreeding or other genetic dysfunctions at low densities; and (3) failure to locate mates (Lewis and Kareiva 1993, Sæther et al. 1996, Courchamp et al. 1999, Stephens and Sutherland 1999, 2000, Berec et al. 2001). 
Because most plant and animal species reproduce sexually, mating failure may be perhaps the most frequent cause of Allee dynamics. A few studies have investigated how matelocation failure may contribute to Allee dynamics but these studies have largely focused on the spatial isolation of individuals: widely dispersed males and females are typically limited in their abilities to locate each other for mating (Hopper and Roush 1993, Wells et al. 1998, Berec et al. 2001, South and Kenward 2001). However, in addition to dispersion in space, mates may be segregated in time (seasonally) and this could greatly impact mating success. The impact of temporal dispersion may be particularly acute in species where reproduction occurs during a discrete season. In particular, for many animal and plant species, the timing of female adult maturation occurs slightly after peak male maturation (Fagerström and Wiklund 1982). This sexual dimorphism in the timing of maturation is referred to as "protandry" (Morbey and Ydenberg 2001) and it may limit mating success, particularly at low population densities.

Calabrese and Fagan (2004) provide the most extensive investigation to date of the role of temporal dispersion and protandry in generating Allee dynamics. They developed a model of mating probability based upon two parameters that characterize the temporal overlap between males and females: the length of the population-level breeding period and the duration of the individual reproductive period. The potential for asynchrony was used to calculate the probability that a female was mated and its consequence on the growth rate of the population. They demonstrated that sexual asynchrony and protandry generated a loss of reproductive potential and contributed to an Allee effect, resulting in population decline at low densities.

While Calabrese and Fagan (2004) broke new ground in demonstrating the potential for developmental dispersion and protrandry to affect mating success and contribute to Allee dynamics, they did not explore the underlying mechanism that governs this temporal variability. While both dispersion in maturation time and protandry are life history attributes, they may be quite plastic and subject to environmental influences. In particular, the development of poikilothermic organisms is largely determined by temperature. Therefore, weather conditions affect the timing of sexual maturation, consequently influencing mating success and expression of an Allee effect. Since climate varies geographically and temporally, this variability could impose limitations in the establishment of invading species. 
In this paper, we model mating success as a function of both variation in developmental time (within each sex) and protandry to demonstrate that both strongly influence mating success. In contrast to the approach of Calabrese and Fagan (2004), we explicitly modeled mating probabilities in discrete time steps instead of considering mating probability as a function of the temporal overlap. We consider a generalized model and then apply it to populations of the gypsy moth, Lymantria dispar, (Lepidoptera: Lymantriidae), a native of Eurasia that is currently in the process of invading North America. We examine how variation in climate throughout North America influences gypsy moth mating success and speculate on how this might impact its ability to invade new habitats. We report that the generalized model successfully predicts gypsy moth mating success given appropriate values of protandry and dispersion of maturation times. We also found that mating failure is likely to contribute to the occurrence of Allee effects, even in relatively dense populations.

\section{Methods}

To explore the effects of temporal variation in maturation on mating success, we developed a generalized model and a gypsy-moth specific model. Both were deterministic, but they differed in the way that maturation times were calculated. The general model represented the distribution of developmental times using a Gaussian function with known variance but the gypsy moth model utilized a previously developed phenological model that predicted the distribution of maturation times based upon daily temperatures. Simulations were performed using the R language (Anonymous 2006). 


\section{Generalized model}

The failure of opposite sexes to locate each other for mating at sparse population levels is affected by both the temporal and spatial isolation of males and females. For simplification, we did not explicitly model spatial isolation and instead focused on the temporal separation, though spatial isolation was implicitly accounted for in our model (Instantaneous mating success, below).

\section{Distribution of maturation times}

Our model was generalized to represent a univoltine species in which mating occurs during a period that follows adult sexual maturation. To model this, we generated synthetic maturation distributions, using Gaussian density functions with varying standard deviations (SD) to simulate the dispersion of maturation of each sex, and varying differences between the mean time of male and female maturation $(\Delta \mathrm{T})$ to simulate protandry. Hereafter, parameters $\mathrm{em}_{\mathrm{d}}$ and $\mathrm{ef}_{\mathrm{d}}$ refer to the rate at which males and females become sexually mature on day $\mathrm{d}$.

\section{Individual longevity}

A second factor included in the model was adult longevity. We arbitrarily assumed $50 \%$ daily survival of each sex though we experimentally tested how variation in longevity impacts population-level mating success. Hereafter survm and survf refer respectively to the daily survival rates of males and females. We also assumed that the maximum longevity of males and females was three days. Adult longevity varies considerably among species and for many species it may greatly exceed three days. However, in these cases, we do not expect that our simplification of longevity would qualitatively alter the relationships explored here. 


\section{Instantaneous mating success}

The third component was a model to calculate the probability of mating given the instantaneous abundance of sexually mature males and females. This model was not spatially explicit, but it accounted for the ability of mates to locate each other in space at a given abundance. Various models of mating success have previously been applied: negative exponential models, rectangular hyperbolic models and power complement models (reviewed by Boukal and Berec 2002). Since these models exhibit very similar behavior (with slight differences in biological representation), we focused only on the negative exponential, assuring no loss of generality. This model assumes that males and females are randomly distributed in space, so the probability of mate encounter is derived from the Poisson probability distribution (Boukal and Berec 2002). Thus, the probability that a female is mated on day $\mathrm{d}$ is given by:

$$
\mathrm{P}_{\mathrm{d}}=1-\exp \left(-\mathrm{sM}_{\mathrm{d}}\right)
$$

where $\mathrm{s}$ is the daily probability that a female is mated in the presence of a single male and $\mathrm{M}_{\mathrm{d}}$ is the number of males potentially able to mate the female on day d, or in other words: the number of males becoming sexually mature on day d, plus the number of males becoming sexually mature on day d-1 which survived one more day, plus the number of males becoming sexually mature on day d-2 which survived two more days. We calculated the abundance of mature males $M_{d}$ available on each day based upon the total number of males (E), the distribution of sexual maturation times $\left(\mathrm{em}_{\mathrm{d}}\right)$ and male longevity (survm).

\section{Combining instantaneous mating success with longevity and maturation times}

When a female lives from day $d$ to day $d+t$, we sum the number of mature males it can encounter on each day from $\mathrm{d}$ to $\mathrm{d}+\mathrm{t}$. Thus, its mating probability is given by:

$$
\mathrm{P}_{\mathrm{d}, \mathrm{t}}=1-\exp \left(-\mathrm{s}\left(\mathrm{M}_{\mathrm{d}}+\ldots+\mathrm{M}_{\mathrm{d}+\mathrm{t}}\right)\right)
$$


For each day d, we calculated the mating success of a female which became sexually mature on day d: either it will not survive to day $d+1$ (the proportion of such females is $e_{d}(1-$ survf) ), or it will survive only to day $d+1$ (the proportion of these females is $\operatorname{ef}_{d} \operatorname{survf}(1-$ survf) ), or it will survive to day $d+2$ (the proportion of these females is $\operatorname{ef}_{d} \operatorname{survf}^{2}$ ). The global probability of mating for the entire population is finally given by:

$$
\mathrm{MS}=\sum_{\mathrm{d}} \operatorname{ef}_{\mathrm{d}}\left((1-\operatorname{survf}) \mathrm{P}_{\mathrm{d}, 0}+\operatorname{survf}(1-\operatorname{survf}) \mathrm{P}_{\mathrm{d}, 1}+\operatorname{survf}^{2} \mathrm{P}_{\mathrm{d}, 2}\right)
$$

\section{Effect of asynchrony on the mating success}

We generated synthetic data in which distributions of male and female sexual maturation dates were based on normal distributions with SD varying across 100 levels between 0.1 and 10 days and with differences in mean male and female emergence times $(\Delta \mathrm{T})$ varying across 11 levels between 0 and 10 days. Then, we used the deterministic model previously described to evaluate the population-level mating success and investigate the effects of both protandry and dispersion in maturation time. We assumed a total number of males $E=100$ and we tested different values of $\mathrm{s}(\mathrm{s}=0.1$ and 0.5 corresponding to low and high mate-finding efficiency respectively).

\section{Effect of longevity rates}

To examine the effect of adult survival on mating success, we assumed $\mathrm{SD}=6$ days and $\Delta \mathrm{T}=$ 6 days. We simulated the population-level mating probability for different survival rates of males and females (survm, survf $=0.2,0.5$, and 0.8 ), and also for varying numbers of males (from $\mathrm{E}=10$ to 100 , by an increment of 10 ) for two cases: $\mathrm{s}=0.1$ and $\mathrm{s}=0.5$.

To compare the relative importance of male and female survival rates, we considered $\mathrm{E}=100$ and $\mathrm{s}=0.1$, then we simulated the mating success for various male survival rates 
$(\operatorname{survm}=0.1$ to 0.9 by 0.01, with survf $=0.5)$ and for various female survival rates (survf $=$ 0.1 to 0.9 by 0.01 , with survm $=0.5)$. We applied linear regression to the results of both sets of simulations $(\mathrm{MS} \sim$ survm and MS $\sim$ survf) and compared the slopes in order to evaluate differences between how male and female survival affect mating success.

\section{Case study: invading North American gypsy moth}

\section{Study system}

The gypsy moth is native to temperate Eurasia but was introduced in North America near Boston in 1869 (Riley and Vasey 1870, Forbush and Fernald 1896). The species has considerably expanded its range but currently occupies slightly less than $30 \%$ of its suitable habitat in North America, as defined by forest composition (Morin et al. 2004), and less than $20 \%$ of the area with highly suitable climate (Gray 2004). New isolated colonies are frequently discovered far from its current North American distribution, mostly as a result of accidental movement of egg masses by humans (Mason and McManus 1981). Since North American gypsy moth populations have been the subject of massive amounts of research, extensive biological data exists for parameterization of the mating success model described above.

\section{Emergence curves}

Because the reproductive period of the gypsy moth begins as soon as adults emerge, we considered the distribution of emergence times to represent the distribution of maturation times. We simulated the timing of male and female emergence $\left(\mathrm{em}_{\mathrm{d}}\right.$ and $\left.\mathrm{ef}_{\mathrm{d}}\right)$ using a previously described phenological model, Gypsy moth life stage model (GLS ver. 3.0; Gray 2004). The GLS model is a composite phenological model, which combines three separate models of egg development for prediapause (Gray et al. 1991), diapause (Gray et al. 2001) 
and postdiapause development (Gray et al. 1995), with models for early larval stages (Logan et al. 1991) and late larval to adult stages (Sheehan 1992). Régnière and Nealis (2002) applied GSL to weather station data and found that predicted timing of both egg hatch and adult emergence closely agreed with the timing of these events observed in the field.

The GLS model was used to predict daily emergence rates for males and females based upon temperature data (daily minimum and maximum) from the time of oviposition (summer) until the time of adult emergence the following summer. Because our simulation was designed to represent a scenario in which an isolated gypsy moth population was founded by an egg mass(s) transported from a single source location, we did not initiate the GLS model with oviposition dates specific for each site where the egg mass was moved to, but instead we used a single oviposition date that would be typical of a single source location in the infested area (1 August).

We applied the model to daily temperature data (minimum, maximum) collected at 7591 meteorological stations through out North America from 1960-2000 (obtained from the Global Historical Climatology Network; Peterson and Vose 1997). Adult emergence curves were generated for each station in each year for which data were available. The model requires temperature data from two consecutive years starting from the date of oviposition until the date of adult emergence. If data from a given weather station were missing on more than 15 consecutive days, GLS fails to produce a prediction, and therefore emergence curves were not calculated. In more occasional instances of missing data, GLS estimates replacement temperature values through interpolation (Gray 2004).

The GLS model accounts for variability in thermal requirements for development within a population. As such, it tracks the development of individuals that complete development to the adult stage, as well as those that do not. Because the model predicted that significant proportions of populations at some locations would not complete development, we 
transformed predictions of daily percentages of starting populations into proportions of males and females that summed to one for each sex over all emergence dates. These proportions defined the daily emergence probabilities $\mathrm{em}_{\mathrm{d}}$ and $\mathrm{ef}_{\mathrm{d}}$ specific for gypsy moth development under each set of temperature conditions. Gray (2004) showed that northern regions of North America are climatically marginal for gypsy moth establishment because late oviposition, slow larval development, and early winter temperatures combine to arrest development in the non cold-hardy prediapause phase. Southern regions of North America are climatically marginal because high winter temperatures are less suitable for diapause development. When the GLS model predicted $<5 \%$ of the population would successfully emerge, we rounded this to zero and assumed that there was no emergence. We found that inclusion of these marginal populations resulted, in some cases, in a gross overestimation of mating success (artificially generated by the model).

\section{Individual longevity}

Based upon previous experimental studies, we assumed that maximum male longevity was three days and their daily survival rate was survm $=0.19$ (Elkinton and Cardé 1980), and that maximum female longevity was three days with a daily survival rate of survf $=0.48$ (Sharov et al. 1995). The contribution of females $>3$ days old is negligible since fertility declines drastically in females older than three days (Richerson et al. 1976).

\section{Model of mating success}

We used the negative exponential model (Eq. 1) to calculate daily mating success based upon male abundance derived from male emergence curves predicted by the GLS model. This instantaneous mating success model was fit $(\mathrm{s}=0.15)$ by Sharov et al. (1995) using daily field measurements of female mating success and male abundance from several locations. At each 
location, mating success was measured by dissection of 18 deployed females and male abundance was measured by the average capture of four pheromone traps. Pheromone-baited traps are a standard method for assessing sparse gypsy moth populations; they are very sensitive at low densities (Elkinton and Cardé 1981), and at these densities they are closely related to population density. Thus, we expressed gypsy moth abundance throughout this paper in terms of males per trap. While the daily mating success model (Eq. 1) uses male abundance from a single day, the overall objective of this case-study was to estimate the relationship between mating success and abundance as measured by season-long trap capture.

\section{Combining instantaneous mating success with longevity and emergence times}

Abundance of males on each day $\left(\mathrm{M}_{\mathrm{d}}\right)$ was derived from the season-long trap capture (TC):

$$
\mathrm{TC}=\mathrm{M}_{1}+\ldots+\mathrm{M}_{\mathrm{n}}+\mathrm{M}_{\mathrm{n}+1}+\mathrm{M}_{\mathrm{n}+2}
$$

where $d=1$ is the first day of emergence, and $d=n$ is the last day.

But these $\mathrm{M}_{\mathrm{d}}$ daily male abundances (measured as daily trap capture), will themselves be composed both of males that emerged that day, as well as surviving males from previous days:

$$
\mathrm{M}_{\mathrm{d}}=\mathrm{em}_{\mathrm{d}} \mathrm{E}+\operatorname{survm}_{\mathrm{em}} \mathrm{d}-1 \mathrm{E}+\operatorname{survm}^{2} \mathrm{em}_{\mathrm{d}-2} \mathrm{E}
$$

where $\mathrm{em}_{\mathrm{d}}$ is the rate of males emerging on day $\mathrm{d}$ and $\mathrm{E}$ the total number of males. Even though $\mathrm{E}$ is expressed in terms of trap capture, it differs from season-long trap capture (TC) because it represents the total number of males that emerged during the entire generation. In contrast, $\mathrm{TC}$ includes $\mathrm{E}$ plus males that survived to subsequent days. Since $\mathrm{em}_{1}+\ldots+\mathrm{em}_{\mathrm{n}}=$ 1 , we can deduce that $\mathrm{TC}=\left(1+\operatorname{survm}+\operatorname{survm}^{2}\right) \mathrm{E}$ and more precisely, $\mathrm{TC}=1.23 \mathrm{E}$ in our case. The various parameters required in the gypsy moth model as well as the generalized model are listed in Table 1.

Simulations were carried-out for various values of season-long trap capture (TC $=10$ 
to 1000 by 10 ), to estimate the relationship between abundance and population-level mating success. These simulations were repeated using temperature data from four locations: Farmville, Virginia and Lakewood, Wisconsin, were located within the current range of the gypsy moth; and Santa Barbara, California and Jackson, Wyoming, were located outside the range distribution. For each location, we calculated the mean mating success over 1960-2000. Also, we fixed season-long trap capture at $\mathrm{TC}=100$ and calculated the mean mating success using temperature data from each of the 7591 North American meteorological stations from 1960-2000 to examine the geographical variation in mating success, both in areas that the gypsy moth has successfully colonized and in areas not yet invaded.

\section{Results}

\section{Generalized model}

Simulations using Eq. 1, 2 and 3 with Gaussian distributions for sexual maturation times illustrate how temporal asynchrony between male and female maturation affects female mating success (Fig. 1a). The daily mating probability $\left(\mathrm{P}_{\mathrm{d}}\right)$ is not in complete phase with the distribution of male maturation times; the curve is extended to the right because of male longevity. The distribution of mated females is shifted quite strongly to the right of the daily mating probability distribution because it is strongly affected by the distribution of emerging females. Earlier emerging females are much more likely to be mated than late emerging females due to a decline in available males. In the case of strong protandry, mainly the first emerging cohort of females contributes to the subsequent generation.

\section{Effect of longevity}

Male survival rates affect the number of males available to mate each day, and consequently the daily mating probability $\left(\mathrm{P}_{\mathrm{d}}\right.$ calculated from Eq. 1). Daily mating probability is 
significantly depressed when male survival is reduced (Fig. 1a-b). The population-level mating success (Eq. 3) increased from MS $=0.46$ to 0.66 as a result of the increase in survm from 0.2 to 0.8 (with survf $=0.5$, Table 2 ). This increase in mating success can be explained by both the increased overlap with females and the elevated availability of males each day.

Female survival rates affect the number of days during which they can potentially encounter mature males and high survival therefore leads to increased mating success. Since the daily mating probability given by Eq. 1 is independent of female abundance, the mating probability curve does not change with increased female longevity (Fig. 1a, 1c). However the probability than a female is mated during its reproductive period does increase slightly from $\mathrm{MS}=0.49$ to 0.65 when the female survival rate increases from 0.2 to 0.8 (with survm $=0.5$, Table 2).

Though both male and female survival rates were positively related to mating success (Fig. 2, Table 2), the effect of male survival was $27 \%$ stronger (the slope estimate was $0.33, \mathrm{p}$ $<0.001$, for the linear regression MS survm and 0.26, p $<0.001$, for MS $\sim$ survf). Mating success is obviously higher for greater levels of mate searching efficiency ( $\mathrm{s}=0.5 \mathrm{vs} 0.1)$ and it is positively related to the abundance of mature males $\mathrm{E}$ (Fig. 2). When mate searching efficiency is high $(\mathrm{s}=0.5)$, effects of survival rates on mating success are more important at low abundance of males. Mating success converges rapidly toward an upper limit with increasing number of males. In contrast, longevity is more important at high male abundance when mate-searching efficiency is low $(\mathrm{s}=0.1)$.

\section{Effect of asynchrony on the mating success}

Both the dispersion in developmental times (SD) and differences between male and female development (protandry, $\Delta \mathrm{T}$ ) affected mating success (Fig. 3). Success declined as either value increased. The effect of protandry was most pronounced when dispersion was low as 
even small differences in developmental times between the sexes almost completely eliminated mating. The intensity of the effect of protandry on mating success increased as mate searching became less efficient $(\mathrm{s}=0.1 \mathrm{vs} \mathrm{s}=0.5$, Fig. $3 \mathrm{a}$ vs $3 \mathrm{~b}$ ). Finally, the influence of dispersion in developmental time on mating success was relatively high in comparison to the effect of survival rates (Fig. 2).

\section{Case study: invading North American gypsy moth}

Simulations based on weather station data indicated that mating success was non-uniform across North America (Fig. 4). Mating success could not be simulated in extremely northern and southern locations because the GLS model predicted extremely low or no emergence of adults (locations represented by grey stars on Fig. 4). The map of mating success clearly showed a central zone stretching across the USA in which mating was expected to be optimal. In contrast, mating success was predicted to be particularly low in other parts of North America, especially in mountainous regions in the west. We examined average mating success in more details (for $\mathrm{TC}=100$ males per trap) at two locations within the current range of the gypsy moth: Farmville, Virginia and Lakewood, Wisconsin; and two locations where the gypsy moth has not yet colonized: Santa Barbara, California and Jackson, Wyoming (Fig. 4). Mating success was greatest at Farmville and lowest in Santa Barbara (Fig. 5, Table 3). These differences between locations can be explained in terms of both dispersion in developmental times and protandry (Fig. 3c). The low mating probability in Jackson was primarily due to a long delay between peak emergence of males and females $(\Delta \mathrm{T}=8.4$ day average) and a relatively low dispersion of emergence dates $(\mathrm{SD}=6.7$ days). The low mating probability in Santa Barbara was apparently the result of a different behavior: the delay between mean male and female emergence was shorter $(\Delta \mathrm{T}=5.2$ day average), but mating apparently failed because there was so much dispersion in emergence dates ( $\mathrm{SD}=13.6$ days). 
One consequence of the Mediterranean Santa Barbara climate is that temperatures

experienced during diapause development are relatively warm and this is known to increase the variability in timing of egg hatch (Masaki 1956), which presumably would lead to highly variable adult emergence times as well. Even though this high variability allows male and female reproductive periods to overlap, it causes a severe decrease in the daily density of mature males. Since the mating probability increases exponentially with the daily number of mature males (Eq. 1), increased dispersion in the emergence curve is unfavorable for mating success.

Mating success values predicted by the generalized model are highly consistent with the values predicted by the more realistic gypsy moth-specific model. Absolute errors were below 0.01 for prediction of the mean mating probability based on the mean protandry and mean variability in males development times (Fig. 3c, Table 3). When we tested the normality of emergence times (using a Jarque Bera test which is based on skewness and kurtosis coefficients, and rejecting normality when $\mathrm{p}<0.05$ ), we found that these data were not normally distributed in more than $60 \%$ of the years, for each of the four locations. Despite this result, both models provided approximately the same result. This result is important because it indicates that it is not necessary to perform detailed simulations (such as performed here for the gypsy moth) to estimate mating success with an acceptable level of accuracy. Instead, one only needs estimates of the variability in development time and protandry and then mating success can be directly estimated from maps, such as those given in Fig. 3.

Simulations indicated that, when season-long trap capture was below 100 males per trap, mating success rarely exceeded $60 \%$ (Fig. 5). The relative magnitude of mating success varied considerably among locations with different climates, but the same pattern of increasing mating success with increasing abundance (measured by trap capture) was evident from simulations using data from all sites. Even at an apparently favorable location, where gypsy moth populations have been established for several years (Farmville, Virginia), mating success was less than $50 \%$ when trap capture was below 60 males per trap. Mating success converged toward an upper limit when season-long trap capture reached 1000 males per trap (which corresponds to the upper bound of season-long trap capture). This limit was approximately 0.90 in Farmville, Lakewood and Santa Barbara but 
considerably lower, around 0.77 , in Jackson. This result suggests that protandry and dispersion in development time act differently. In Santa Barbara, dispersion in development time was particularly high and mating success was quite low at low population density but increased to the same limit as in favorable sites. In contrast, emergence curves in Jackson were characterized by a very long delay between male and female mean emergence time. This protandry seems slightly more favorable than the long dispersion of developmental time at low population density, but mating success is substantially lower than in other locations at high population density.

To more fully understand the causes of mating failure, we illustrate a simulation from a single location (Farmville, Virginia) in a single year (1997) (Fig. 1d ). Females emerging early had a very high mating probability (approaching 100\%) since their emergence occurred during the period of highest male emergence. Females emerging later had very low mating success (approaching 0\%). These females that emerge at particularly late dates greatly diminish the population-level mating success.

\section{Discussion}

Reproductive asynchrony has been mainly considered adaptive for populations, notably in cases of strong environmental stochasticity (Wiklund and Fagerström 1977, Waldbauer 1978, Simmons and Johnston 1997). However, this study supports the conclusion drawn by Calabrese and Fagan (2004) that asynchrony can actually generate an Allee dynamics at low densities, which could contribute to extinction. It is worth noting that the main contributor to low mating success appears to come from individuals with particularly fast or slow development (Fig. 3a-b). However, it has also been speculated that environmental stochasticity may cause selection for developmental outliers (Post et al. 2001). Thus, natural selection for this life-history trait would result from two opposing forces: (1) mate-location that could trigger selection against protandry, and (2) various factors traditionally considered as beneficial (e.g. an increase in the male mating opportunity or decrease in the waiting cost of females, Morbey and Ydenberg 2001). Since protandry is an adaptive behavior that has 
been maintained for thousands of years throughout biological evolution in many species, the negative effects on mate location described here must be offset by even stronger positive selection for this trait.

Our model indicates that under virtually all situations, temporal asynchrony is likely to cause increased mating failure at lower densities. Such Allee effects have been shown to be important determinants of the establishment of newly founded populations and the spread of populations following establishment (Lewis and Kareiva 1993, Taylor and Hastings 2004). In particular, Allee effects have been shown to be critical in determining the establishment and spread of invading gypsy moth populations (Liebhold and Bascompte 2003, Johnson et al. 2006, Tobin et al. 2007). The results of our simulations thus indicate that mate location may be an important contributor to Allee effects. Of course, mating success represents just a single component of the demographics of any population; as such, quantification of Allee effects cannot be derived alone from the results of this study. However, these results do support the concept that mating failure is a major contributor to an Allee effect in the gypsy moth. In the future, it should be possible to combine the results of this study with other demographic models of gypsy moth dynamics that account for all sources of mortality and reproduction, to estimate Allee effects.

Recent analyses of historical gypsy moth invasion data indicate that geographical variation in Allee effects influence geographical variation in rates of gypsy moth spread (Tobin et al. 2007). In this study, we have shown that mating success can be expected to exhibit considerable geographical variability, with a central zone stretching across the USA where mating rates are highest (Fig. 4). Most of the current distribution of the gypsy moth in North America lies outside of this optimal area. Thus, it is likely that the climate-related geographical variation in mating success represents a component of geographical variability 
in Allee effects and this could have affected past rates of gypsy moth spread, as well as

influence its future rate of spread.

We have demonstrated the potential for geographic variation in climate to produce geographic variation in mating success under an assumption of constant life history and thermal requirements for development across the area. These results add another dimension to our understanding of geographical variation in habitat suitability for the gypsy moth. Previous analyses characterized the geographical distribution of suitable forest host tree species (Liebhold et al. 1997, Morin et al. 2004). Gray (2004) used a network of weather station records, similar to that utilized here, to characterize geographical variation in climatic suitability for establishment based on life cycle completion (i.e. the ability of an introduced population to complete successive generations). The results presented here indicate that geographical variation in climatic suitability for mating is yet another component of habitat suitability. Although coastal California is potentially suitable for gypsy moth development (Gray 2004) and contains suitable host trees (Liebhold et al. 1997), our results indicate that the probability of mating may be relatively low (Fig. 3c, 4, $5)$.

Our results provide new insights concerning the potential for establishment of new

gypsy moth populations across North America, however we should moderate our

interpretation. While our model accounted for geographical variability in maturation times, it assumed that other parameters (e.g. male and female longevity and survival) were constant.

Substantial geographical variation in these traits could be expected to alter the model's predictions. This study provides a preliminary understanding of mating failure in this species and while assuming various hypotheses, it rigorously describes the underlying mechanism for this failure.

As a matter of simplicity, simulations described here were intended to represent a scenario where a gypsy moth egg mass was transported from a single location and, therefore, our phenology simulations were based upon a single date of oviposition (1 August). In practice, the equilibrium oviposition date varies geographically with climate (Gray 2004). We conducted additional simulations in which the date of oviposition was varied and we found that through most of the range of equilibrium oviposition dates reported by Gray (2004), there was little variation in predicted mating success at most locations. Thus, the source location of an egg mass transported to most portions of North America could be expected to have little 
impact on mating success. In contrast, oviposition date does affect the probability that a population can complete development (Gray 2004) and thus the identity of the source population is likely to affect local establishment.

Our generalized model coupled with a species-specific investigation provides further evidence of the importance of mating failure due to temporal asynchrony between male and female maturation times. This mechanism alone, or in addition to other factors generating Allee effects (such as spatial isolation of individuals or other factors not associated with matefinding), could contribute to the decline of a population, or the failure of a population to establish. As a result, the causes of Allee effects should be clearly identified to understand more precisely the dynamics of expanding or declining populations.

Acknowledgements - We thank E. Luzader for technical assistance in preparing climatic data. Bill Fagan volunteered comments that were useful in conceiving this work. Patrick Tobin provided useful advice and assistance with computational resources. Takehiko Yamanaka, Kevin Thorpe and Patrick Tobin shared useful comments on an earlier draft of this manuscript.

\section{References}

Allee, W.C. et al. 1949. Principles of animal ecology. - W. B. Saunders, Philadelphia, PA. Anonymous 2006. R: a language and environment for statistical computing. R Development Core Team. - R Foundation for Statistical Computing, Vienna, Austria. URL http://www.R-project.org .

Berec, L. et al. 2001. Linking the Allee effect, sexual reproduction, and temperaturedependent sex determination via spatial dynamics. - Am. Nat. 157: 217-230. 
Boukal, D. S. and Berek, L. 2002. Single-species models of the Allee effect: extinction boundaries, sex ratios and mate encounters. - J. Theor. Biol. 218: 375-394.

Calabrese, J. M. and Fagan, W. F. 2004. Lost in time, lonely, and single: reproductive asynchrony and the Allee effect. - Am. Nat. 164: 25-37.

Courchamp, F. et al. 1999. Inverse density dependence and the Allee effect. - Trends Ecol. Evol. 14: 405-410.

Drake, J. M. and Lodge, D. M. 2006. Allee effects, propagule pressure and the probability of establishment: risk analysis for biological invasions. - Biol. Invas. 8: 365-375.

Elkinton, J. S. and Cardé, R. T. 1980. Distribution, dispersal, and apparent survival of males gypsy moths as determined by capture in pheromone-baited traps. - Entomol. Soc. Am. 9: 729-737.

Elkinton, J. S. and Cardé, R. T. 1981. The use of pheromone traps to monitor distribution and population trends of the gypsy moth. - In: Mitchell, E. R. (ed.), Management of insect pests with semiochemicals: concepts and practice. Plenum, pp. 41-55.

Fagerström, T. and Wiklund, C. 1982. Why do males emerge before females? Protandry as a mating strategy in male and female butterflies. - Oecologia (Berl.) 52: 164-166.

Forbush, E. H. and Fernald, C. H. 1896. The gypsy moth. - Wright and Potter, Boston, MA.

Gray, D. R. 2004. The gypsy moth life stage model: landscape-wide estimates of gypsy moth establishment using a multi-generational model. - Ecol. Modell. 176: 155-171.

Gray, D. R. et al. 1991. Toward a model a model of gypsy moth egg phenology: using respiration rates of individual eggs to determine temperature-time requirements of prediapause development. - Environ. Entomol. 20: 1645-1652.

Gray, D. R. et al. 1995. Further advances toward a model of gypsy moth (Lymantria dispar (L.)) egg phenology: respiration rates and thermal responsiveness during diapause, and age-dependent developmental rates in postdiapause. - J. Insect Physiol. 41: 247-256. 
Gray, D.R., Ravlin, F.W. and Braine, J.A. 2001. Diapause in the gypsy moth: a model of inhibition and development. - J. Insect. Physiol. 47: 173-184.

Hopper, K. R. and Roush, R. T. 1993. Mate finding, dispersal, number released, and the success of biological control introductions. - Ecol. Entomol. 18: 321-331.

Johnson, D. et al. 2006. Allee effects and Pulsed invasion by the gypsy moth. - Nature 444: 361-363.

Lande, R. 1993. Risks of population extinction from demographic and environmental stochasticity and random catastrophes. - Am. Nat. 142: 911-927.

Legendre, S. et al. 1999. Demographic stochasticity and social mating system in the process of extinction of small populations: the case of passerines introduced to New Zealand. - Am. Nat. 153: 449-463.

Lewis, M. A. and Kareiva, P. 1993. Allee dynamics and the spread of invading organisms. Theor. Popul. Biol. 43: 141-158.

Liebhold, A. and Bascompte, J. 2003. The Allee effect, stochastic dynamics and the eradication of alien species. - Ecol. Lett. 6: 133-140.

Liebhold, A. M. et al. 1997. Evaluation of forest susceptibility to the gypsy moth across the conterminous United States. - J. For. 95: 20-24.

Logan, J. A. et al. 1991. Modeling environment for simulation of gypsy moth (Lepidoptera: Lymantriidae) larval phenology. - Environ. Entomol. 20: 1516-1525.

Ludsin, S. A. and Wolfe, A. D. 2001. Biological invasion theory: Darwin's contributions from the origin of species. - Bioscience 51: 780-789.

Masaki, S. 1956. The effect of temperature on the termination of diapause in the egg of Lymantria dispar Linne. (Lepidoptera: Lymantriidae). - Jpn J. Appl. Zool. 21: 148157.

Mason, C. J. and McManus, M. L. 1981. Larval dispersal of the gypsy moth. - In: Doane, 
C.C. and McManus, M. L. (eds), The gypsy moth: research toward integrated pest management. USDA Tech. Bull. 1584, pp. 161-202.

May, R. M. 1973. Stability and complexity in model ecosystems. - Princeton Univ. Press. Morbey, Y. E. and Ydenberg, R. C. 2001. Protandrous arrival timing to breeding areas: a review. - Ecol. Lett. 4: 663-673.

Morin, R. S. et al. 2004. Mapping host-species abundance of three major exotic forest pests. USDA For. Serv. Northeastern Res. Stn Res. Paper NE-726.

Murray, J. D. 1990. Mathematical biology. - Springer.

Peterson, T. C. and Vose, R. S. 1997. An overview of the global historical climatology network temperature data base. - Bull. Am. Meteorol. Soc. 78: 2837-2849.

Post, E. et al. 2001. Reproductive asynchrony increases with environmental disturbance. Evolution 55: 830-834.

Régnière, J. and Nealis, V. 2002. Modeling seasonality of gypsy moth (Lepidoptera: Lymantriidae), to evaluate probability of its persistence in novel environments. - Can. Entomol. 134: 805-824.

Richerson, J. V. et al. 1976. Sexual activity of the gypsy moth. - Am. Midl. Nat. 95: 299-312.

Riley, C. V. and Vasey, G. 1870. Imported insects and native American insects. - Am. Entomol. 2: 110-112.

Sæther, B. E. et al. 1996. Life history variation, population processes and priorities in species conservation: towards a reunion of research paradigms. - Oikos 77: 217-226.

Sharov, A. A. et al. 1995. Prediction of gypsy moth (Lepidoptera: Lymantriidae) mating success from pheromone trap counts. - Environ. Entomol. 24: 1239-1244.

Sheehan, K. 1992. User's guide to GMPHEN: Gypsy moth phenology model. - USDA For. Serv. Gen. Tech. Rep. NE 158. 
Simmons, A. M. and Johnston, M. O. 1997. Developmental instability as a bet-hedging strategy. - Oikos 80: 401-406.

South, A. B. and Kenward, R. E. 2001. Mate finding, dispersal distances and population growth in invading species: a spatially explicit model. - Oikos 95: 53-58.

Stephens, P. A. and Sutherland, W. J. 1999. Consequences of the Allee effect for behavior, ecology and conservation. - Trends Ecol. Evol. 14: 401-405.

Stephens, P. A. and Sutherland, W. J. 2000. Vertebrate mating systems, Allee effects and conservation. - In: Apollonio, M. et al. (eds.), Vertebrate mating systems (chapter 9). World Scientific Publishing.

Taylor, C. M. and Hastings, A. 2004. Finding optimal control strategies for invasive species: a density-structured model for Spartina alterniflora. - J. Appl. Ecol. 41: 1049-1057.

Taylor, C. M. and Hastings, A. 2005. Allee effects in biological invasions. - Ecol. Lett. 8: 895-908.

Tobin, P. C. et al. 2007. Invasion speed is affected by geographic variation in the strength of Allee effects. - Ecol. Lett. 10: 36-43.

Waldbauer, G. P. 1978. Phenological adaptation and polymodal emergence patterns of insects. - In: Dingle, H. (ed.), Evolution of insect migration and diapause. Springer, pp. 127-144.

Wells, H. et al. 1998. Mate location, population growth and species extinction. - Biol. Conserv. 86: 317-324.

Wiklund, C. and Fagerström, T. 1977. Why do males emerge before females? A hypothesis to explain the incidence of protandry in butterflies. - Oecologia (Berlin) 31: 153-158.

Williamson, M. and Fitter, A. 1996. The varying success of invaders. - Ecology 77: 16611666. 


\section{TABLES}

Table 1. Parameters required in our models (G: generalized model; GM: Gypsy moth model).

\begin{tabular}{|c|c|c|}
\hline Parameters & Description & Models \\
\hline $\mathrm{S}$ & $\begin{array}{l}\text { Instantaneous mating probability in } \\
\text { presence of one mature male. }\end{array}$ & G \& GM \\
\hline survm (survf) & $\begin{array}{l}\text { Daily survival rate of males (females) } \\
\text { during the reproductive period. }\end{array}$ & G \& GM \\
\hline$e m_{d}\left(e f_{d}\right)$ & $\begin{array}{l}\text { Daily rate of males (females) becoming } \\
\text { sexually mature. }\end{array}$ & G \& GM \\
\hline$\Delta \mathrm{T}$ & $\begin{array}{l}\text { Protandry (delay between male and female } \\
\text { mean time of sexual maturation); required } \\
\text { to calculate } \mathrm{em}_{\mathrm{d}} \text { and } \mathrm{ef}_{\mathrm{d}} \text {. }\end{array}$ & G \\
\hline $\mathrm{SD}$ & $\begin{array}{l}\text { Variability in development times (standard } \\
\text { deviation of sexual maturation times); } \\
\text { required to calculate } \mathrm{em}_{\mathrm{d}} \text { and } \mathrm{ef}_{\mathrm{d}} \text {. }\end{array}$ & G \\
\hline $\mathrm{E}$ & Total number of males. & G \\
\hline $\mathrm{TC}$ & $\begin{array}{l}\text { Season-long trap capture (cumulative } \\
\text { number of daily abundance of mature } \\
\text { males). }\end{array}$ & GM \\
\hline
\end{tabular}


Table 2. Effects of adult longevity on mating success simulated by the generalized model (with $\mathrm{s}=0.1, \mathrm{E}=100$ males, $\mathrm{SD}=6$ days and $\Delta \mathrm{T}=6$ days).

\begin{tabular}{l|lll}
\hline survf & 0.2 & 0.5 & 0.8 \\
\hline 0.2 & & & \\
0.5 & 0.39 & 0.49 & 0.60 \\
0.8 & 0.46 & 0.56 & 0.66 \\
\hline
\end{tabular}


Table 3. Estimation of the mean mating success over $n$ years in four locations, resulting from the gypsy moth specific model, MS(GM), and from the generalized model, $\mathrm{MS}(\mathrm{G})$ using the mean standard deviation of the males emergence curve $\left(\mathrm{SD}_{\mathrm{M}}\right)$ and the mean difference in the mean emergence time between females and males $(\Delta \mathrm{T})$ to determine the mating success on Fig. 3c.

\begin{tabular}{l|c|c|c|c|c}
\hline Locations & $\mathrm{n}$ & $\Delta \mathrm{T}_{ \pm \mathrm{SD}}$ & $\mathrm{SD}_{\mathrm{M}} \pm \mathrm{SD}$ & $\mathrm{MS}(\mathrm{GM}) \pm \mathrm{SD}$ & $\mathrm{MS}(\mathrm{G})$ \\
\hline Farmville, Virginia & 38 & $3.5 \pm 0.43$ & $2.8 \pm 0.5$ & $0.62 \pm 0.06$ & 0.63 \\
Lakewood, Wisconsin & 26 & $4.5 \pm 0.69$ & $3.7 \pm 0.7$ & $0.56 \pm 0.04$ & 0.57 \\
Jackson, Wyoming & 35 & $8.4 \pm 2.68$ & $6.7 \pm 2.3$ & $0.42 \pm 0.07$ & 0.43 \\
Santa Barbara, California & 22 & $5.2 \pm 0.43$ & $13.6 \pm 2.9$ & $0.37 \pm 0.05$ & 0.36 \\
\hline
\end{tabular}




\section{FIGURES}

Fig. 1. Effects of different survival rates on mating duccess (MS): (a) survm $=0.5$ and survf $=$ 0.5, (b) $\operatorname{survm}=0.2$ and survf $=0.5$, (c) survm $=0.5$ and survf $=0.2$. For these graphs, temporal distribution of males and females becoming sexually mature was generated using a Gaussian function with a standard deviation $\mathrm{SD}=6$ days and a time-lag between both sexes $\Delta \mathrm{T}=6$ days, $\mathrm{E}=100$ males and $\mathrm{s}=0.1$. We also plotted a similar graph in the specific case of gypsy moth (d) using emergence curves given by the GLS model in Farmville in 1997 (survm $=0.19$, survf $=0.48, \mathrm{TC}=100$, and $\mathrm{s}=0.15)$. We calculated the daily mating probability only based on the mature males available (Eq. 1) (bold line), and the proportion of females becoming mature on day $\mathrm{d}$ which can effectively be mated during their reproductive period (and life span) (MS calculated from Eq. 3, and then we applied this probability to the $\%$ of females, see dark shaded area).

Fig. 2. Effect of varying survival rates on mating success using synthetic Gaussian emergence distributions $(\mathrm{SD}=6$ days, $\Delta \mathrm{T}=6$ days $)$ and different values for $\mathrm{s}(\mathrm{s}=0.1$ and 0.5 corresponding respectively to a strong and weak Allee effect), with $E=100$ males.

Figure 3. Mating success resulting of normal distribution of sexual maturation times, with various standard deviations SD (y-axis) and delays between males and females $\Delta \mathrm{T}$ (x-axis): (a) $s=0.1$ (low mate-finding efficiency), survm $=\operatorname{survf}=0.50, E=100$ males; (b) $s=0.5$ (high mate-finding efficiency), survm $=\operatorname{survf}=0.50, \mathrm{E}=100$ males; $(\mathrm{c}) \mathrm{s}=0.15$, survm $=$ 0.19, survf $=0.48$ (values for gypsy moth), $\mathrm{TC}=100$ males. Stars symbols refer to four stations (Farmville, Virginia; Lakewood, Wisconsin; Santa Barbara, California and Jackson, 
Wyoming). We calculated the mean standard deviation of male emergence curves and the mean delay between male and female emergence peaks using the GLS model.

Fig. 4. Average mating success (MS) over 1960-2000 $(\mathrm{s}=0.15$, $\operatorname{survm}=0.19$, $\operatorname{survf}=0.48$, $\mathrm{TC}=100$ males). To draw the border, we used the coastline extractor from the National Geophysical Data Center, NOAA Satellite and Information Service (http://www.ngdc.noaa.gov/ngdc.html).

Fig. 5. Average mating success (over 1961-2000) for various values of trap captures, TC, and in several locations $(\mathrm{s}=0.15$, survm $=0.19$, survf $=0.48)$. Santa Barbara, California and Jackson, Wyoming were chosen because of their very low predicted mating success; Farmville, Virginia and Lakewood, Wisconsin were chosen as references for currently colonized areas. 
Figure 1.

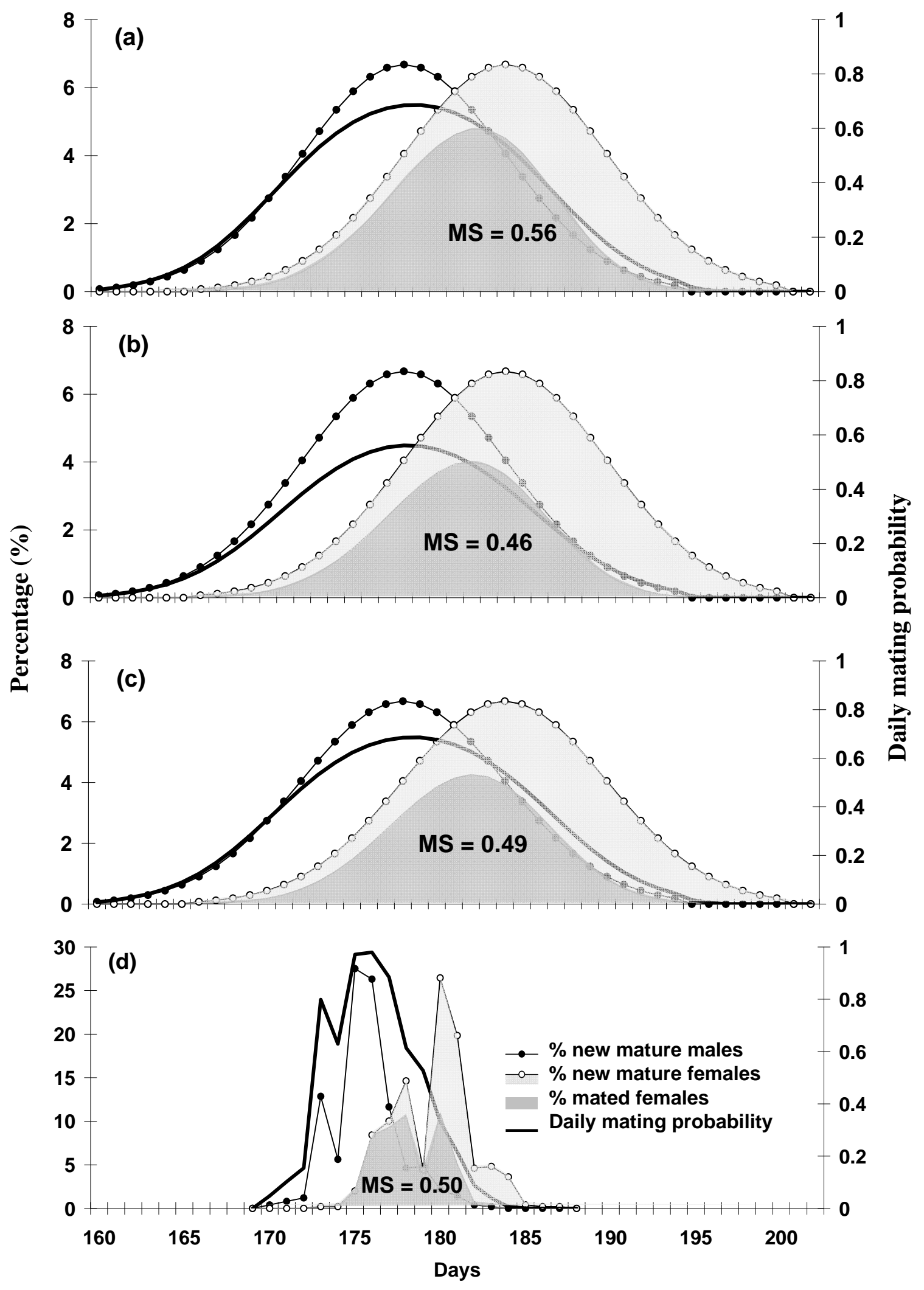

(Author: Robinet, C.) 
Figure 2.

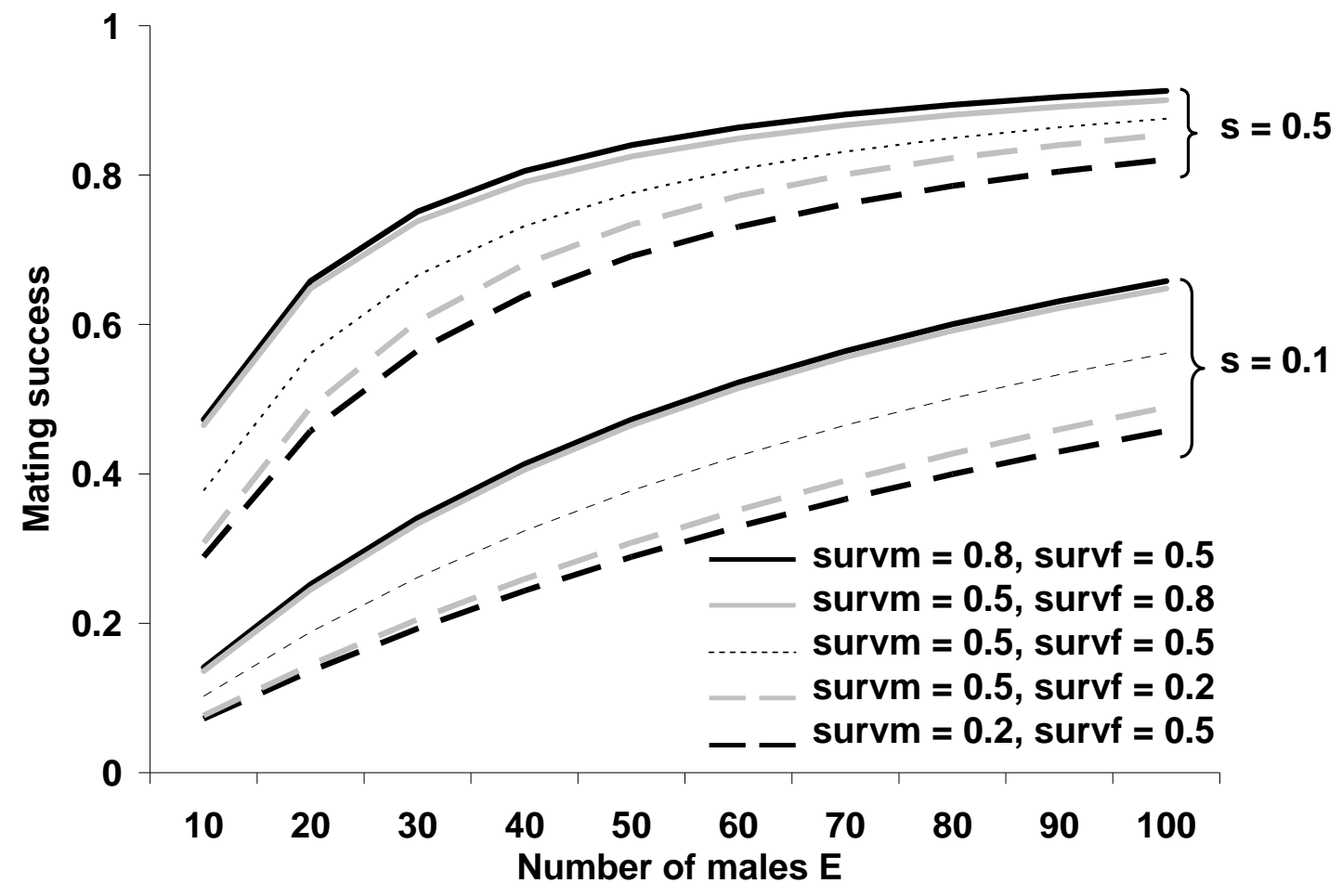

(Author: Robinet, C.) 
Figure 3.
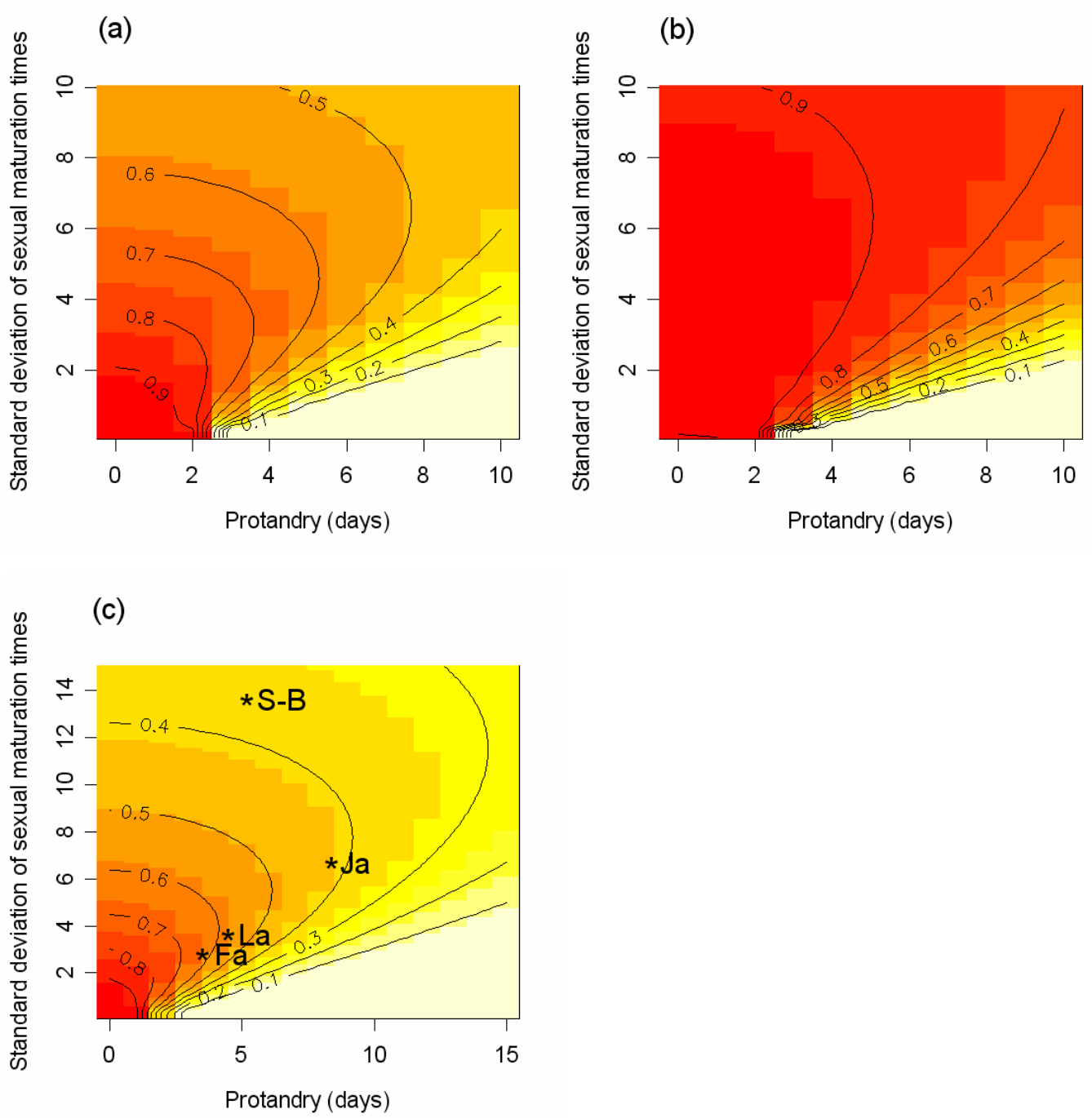

(Author: Robinet, C.) 
Figure 4.

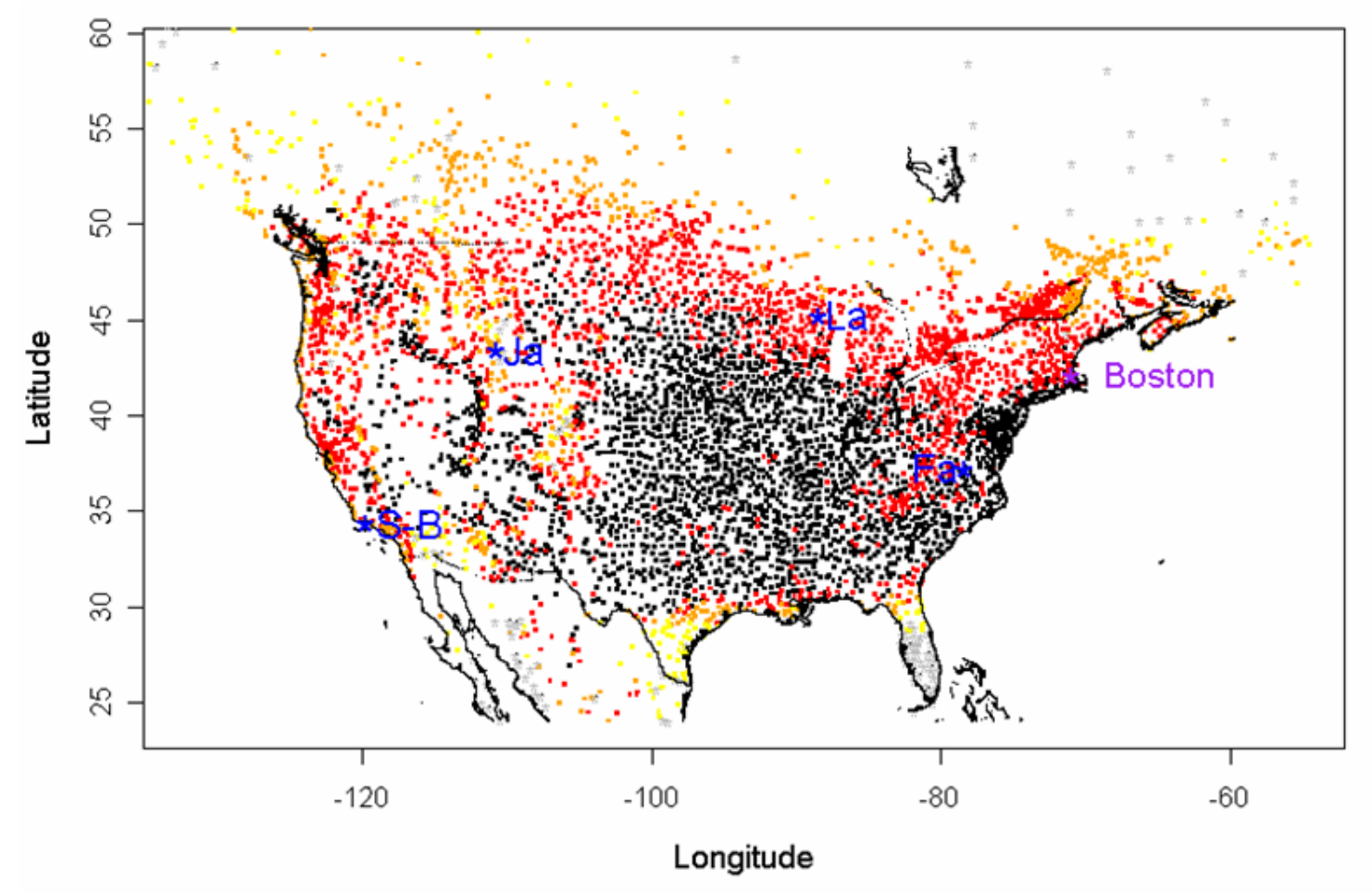

$=0 \leq \mathrm{MS}<0.25$

॥ $0.25 \leq \mathrm{MS}<0.50$

- $0.50 \leq \mathrm{MS}<0.60$

- $0.60 \leq \mathrm{MS} \leq 1$

* No emergence

(Author: Robinet, C.) 
Figure 5.

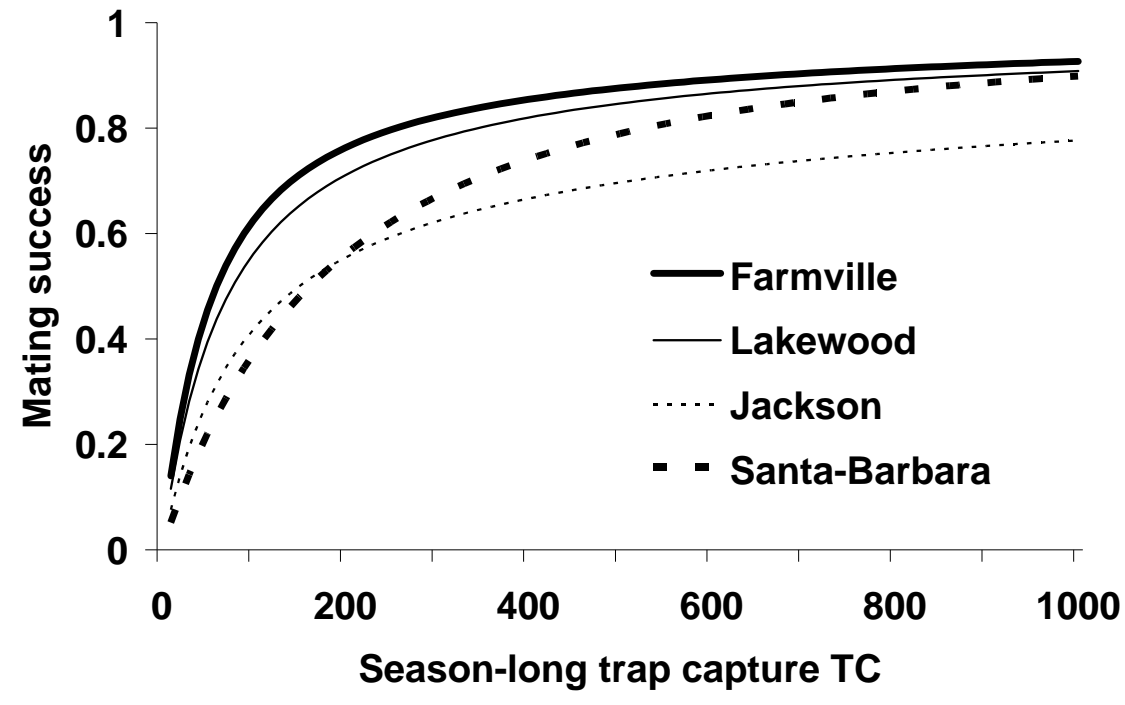

(Author: Robinet, C.) 